\title{
Lamina Propria and Olfactory Bulb Ensheathing Cells Exhibit Differential Integration and Migration and Promote Differential Axon Sprouting in the Lesioned Spinal Cord
}

\author{
Miranda W. Richter, ${ }^{1}$ Patrick A. Fletcher, ${ }^{1}$ Jie Liu, ${ }^{2}$ Wolfram Tetzlaff, ${ }^{2}$ and A. Jane Roskams ${ }^{1}$ \\ ${ }^{1}$ Department of Zoology and ${ }^{2}$ International Collaboration on Repair Discoveries, University of British Columbia, Vancouver, British Columbia, Canada V5Z \\ $4 \mathrm{H} 4$
}

Olfactory bulb-derived (central) ensheathing cell (OB OEC) transplants have shown significant promise in rat models of spinal cord injury, prompting the use of lamina propria-derived (peripheral) olfactory ensheathing cells (LP OECs) in both experimental and clinical trials. Although derived from a common embryonic precursor, both sources of OECs reside in different nervous system compartments postnatally, and their ability to promote regeneration and efficacy after transplantation may differ depending on both their source and mode of transplantation. Here, we have purified green fluorescent protein-expressing LP and OB OECs, assayed their biological differences in vitro, and transplanted them acutely either directly into or rostral and caudal to a dorsolateral funiculus crush. LP and OB OECs exhibit multiple morphological and antigenic similarities in vitro, and, after transplantation, they both attenuate lesion and cavity formation and promote angiogenesis, endogenous Schwann cell infiltration, and axonal sprouting. However, an increased mitotic rate and migratory ability of LP OECs in vitro was reflected in vivo by their superior ability to migrate within the spinal cord, reduce cavity formation and lesion size, and differentially stimulate outgrowth of axonal subpopulations compared with OB OECs. An undesired behavior (autotomy) was also significantly enhanced by LP OEC, over OB OEC, transplantation. These results suggest that LP and OB OECs exhibit intrinsic biological differences that, after transplantation into the lesioned CNS, result in differences in postlesion spinal cord neuropathology and anatomical and behavioral regeneration outcomes that also vary depending on direct versus rostrocaudal transplantation.

Key words: regeneration; olfactory; glia; p75(NGFR); spinal cord injury; rubrospinal; monoaminergic; substance P

\section{Introduction}

The abortive regeneration of CNS neurons is in stark contrast to the renewal capacity of the olfactory system (Graziadei et al., 1978 , 1979). Reconstitution of the olfactory neuraxis can occur even after central axotomy (Zigova et al., 1992). This axonal growth within the CNS has been partially attributed to olfactory ensheathing cells (OECs), resident in the peripheral and central olfactory neuraxis (Doucette, 1990). For this reason, the therapeutic potential of olfactory bulb-derived (OB) OECs to promote recovery from CNS lesions to descending and ascending spinal tracts (Li et al., 1998; Ramon-Cueto et al., 2000; Lu et al., 2002; Nash et al., 2002; Keyvan-Fouladi et al., 2003), primary afferents (Ramon-Cueto and Nieto-Sampedro, 1994; Li et al., 2003) and remyelination of injured/demyelinated spinal cords (Franklin et al., 1996; Imaizumi et al., 1998; Sasaki et al., 2004) have been

Received May 14, 2005; revised 0ct. 3, 2005; accepted 0ct. 5, 2005

This work was supported by the International Spinal Research Trust (A.J.R.), a Canadian Institutes of Health Research (CIHR) training fellowship and the Michael Smith Foundation for Health Research Studentship (M.W.R.) and by CIHR (W.T.). We thank Edmund Au and Erin Currie for technical assistance, members of the Roskams laboratory for ideas and discussion, and Mark Tuczynski for comments on this manuscript.

Correspondence should be addressed to Dr. A. Jane Roskams, Department of Zoology, University of British Columbia, 6270 University Boulevard, Vancouver, British Columbia, Canada V6T 1Z4.E-mail: roskams@zoology.ubc.ca. DOI:10.1523/JNEUROSCI.3632-05.2005

Copyright $\odot 2005$ Society for Neuroscience $\quad 0270-6474 / 05 / 2510700-12 \$ 15.00 / 0$ tested and yielded variable yet positive outcomes. Lamina propria-derived (LP) OECs have been tested only recently for their ability to promote regeneration after lesion (Lu et al., 2001, 2002; Ramer et al., 2004a,b), despite the ongoing clinical use of LP tissue in spinal cord injury (SCI) treatment (Senior, 2002; Huang et al., 2003).

LP and OB OECs, derived from a common progenitor in the olfactory mucosa (Carter et al., 2004), ensheath and promote the growth of olfactory receptor neuron axons as they exit the olfactory epithelium and extend toward the OB (Williams et al., 2004). As LP OECs enter the nerve fiber layer of the OB, they differentiate into OB OECs, where they associate with astrocytes (Au et al., 2002). Thus, although LP and OB OECs possess similarities in morphology and function in vitro (Au and Roskams, 2003; Jani and Raisman, 2004), subtle differences in ensheathing behavior, their distinct roles in the olfactory neuraxis, and their different maturational states suggest they may exhibit different properties when transplanted after SCI.

Groups have already reported varying regeneration outcomes after dorsal rhizotomy and transplantation of OB versus LP OECs (Ramon-Cueto and Nieto-Sampedro, 1994; Ramer et al., 2004a; Riddell et al., 2004). In these cases, the mode of transplantation and proximity of transplanted cells to the lesion site could influence integration and long-term cell survival of transplanted cells. 
To assess how these differences may arise from different OEC sources, methods of transplantation, and assessment measures, it has become important to compare the regeneration-promoting abilities of LP and OB OECs within the same experiment. Here, we have purified transgenic enhanced green fluorescent protein (eGFP)-expressing OECs from the lamina propria and from the nerve fiber layer of the same mice. After establishing their expansion and phenotype in vitro, we acutely transplanted them directly or rostrocaudally into a dorsolateral funiculus crush. Differences examined include interactions with host glia, their ability to promote directional angiogenesis, and their migratory properties within the spinal cord. Furthermore, we have assessed regenerative and sprouting differences between LP and OB OECtreated animals and demonstrated differences in autotomy resulting from transplantation of these two cell populations.

\section{Materials and Methods}

Cell preparation and purification. $L P$ OEC cell culture. $\mathrm{GFP}^{+}$LP OECs were harvested from the olfactory mucosa of postnatal day 5 (P5) transgenic mice, homozygous for eGFP [GFP-U-NAGY; generated by Andreas Nagy, University of Toronto, Toronto, Ontario, Canada (kind gift from Frank Jirik, University of Calgary, Calgary, Alberta, Canada) expressed under the $\beta$-actin promoter and driven by the cytomegalovirus enhancer (Au and Roskams, 2003). The entire olfactory mucosa, including turbinates and septum, was dissected from $8-10$ pups, mechanically dissociated, and treated with $0.6 \mathrm{mg} / \mathrm{ml}$ collagenase D (Roche Products, Indianapolis, IN), $3 \mathrm{U} / \mathrm{ml}$ dispase I (Roche Products), $15 \mu \mathrm{g} / \mathrm{ml}$ hyaluronidase (Sigma, St. Louis, MO), $0.5 \mathrm{mg} / \mathrm{ml}$ bovine serum albumin (MP Biomedicals, Irvine, CA), and $100 \mathrm{U} / \mathrm{ml}$ DNase I (Sigma) for $1 \mathrm{~h}$ at $37^{\circ} \mathrm{C}$, before centrifugation and plating. Initial plating in MEM-D-valine, 10\% fetal bovine serum (FBS), and $100 \mathrm{U} / \mathrm{ml}$ penicillin/streptomycin $(\mathrm{P} / \mathrm{S})$ was followed $4-5 \mathrm{~d}$ later by purification using anti-Thyl.1-mediated complement lysis as described previously, to remove contaminating fibroblasts (Au and Roskams, 2003). Cells were replated in DMEM/F-12, $10 \% \mathrm{FBS}$, and $100 \mathrm{U} / \mathrm{ml} \mathrm{P} / \mathrm{S}$ and allowed to grow for an additional $4-6 \mathrm{~d}$, when they were again subjected to Thyl.1-mediated complement lysis. LP OECs were plated at a density of $5600 \mathrm{cells} / \mathrm{cm}^{2}$ into T75 flasks for transplantation. The time from dissection to transplantation varied from 14 to $16 \mathrm{~d}$ in vitro (DIV).

$O B$ OEC cell culture. From the same litter of P5 eGFP transgenic mice, OB OECs were harvested by sagittally bisecting the head, removing the meningeal covering of the olfactory bulb, using a scalpel to partition the rostralmost quarter of the olfactory bulb, and extracting the portion of the nerve fiber layer next to the cribriform plate. Nerve fiber layers were dissociated and cultured as described by Ramon-Cueto et al. (1998). Briefly, digestion by $0.1 \%$ trypsin for $15 \mathrm{~min}$ at $37^{\circ} \mathrm{C}$ was followed by dissociation by multiple passes through fire-polished pipettes, and the cells were seeded into poly-L-lysine (PLL) $(50 \mu \mathrm{g} / \mathrm{ml}$ in $15 \mathrm{~mm}$ sodium borate buffer; Sigma) pretreated flasks ( $1 \mathrm{~h}$ at room temperature) containing DMEM/F-12, supplemented with $2 \mathrm{~mm}$ L-glutamine, $10 \% \mathrm{FBS}$, $50 \mu \mathrm{g} / \mathrm{ml}$ gentamycin, and $100 \mathrm{U} / \mathrm{ml}$ P/S. After 5-6 DIV, when cells had grown to $\sim 80 \%$ confluency, OB OECs were purified by immunopanning. Detached cells were suspended in DMEM/F-12 with 10\% FBS, and 500,000 cells were plated onto each $96 \mathrm{~mm}$ Petri dish, pretreated with (1) biotinylated goat-anti rabbit IgG antibody $\left(3 \mu \mathrm{g} / \mathrm{ml}, 12 \mathrm{~h}, 4^{\circ} \mathrm{C}\right.$; Vector Laboratories, Burlingame, CA) and (2) rabbit anti-low-affinity nerve growth factor receptor (1:500, $1 \mathrm{~h}$ at room temperature, $\mathrm{p} 75$; Chemicon, Temecula, CA). Cells were incubated for $30 \mathrm{~min}$ at $37^{\circ} \mathrm{C}$, unbound cells were then washed away, and bound cells were detached using a cell lifter. The 30 min immunopanning incubation was used because it produced the greatest purity of OB OEC cultures, with an average of $92 \%$ p $75-$ positive cells $(n=4)$. OB OECs were subcultured once more before being plated at a density of $6500 \mathrm{cells} / \mathrm{cm}^{2}$ into T75 flasks for transplantation. The time from dissection to transplantation was between 14 and 16 DIV.

Cell harvest for transplantation. Before transplantation, the cells from one T75 flask of LP or OB OECs were detached using 0.25\% trypsin $/ 1 \%$ EDTA, followed by washing in PBS and resuspension at a concentration of 50,000-60,000 cells/ $\mu \mathrm{l}$ in DMEM/F-12. These cells were immediately transplanted into two recipient rats, ensuring that every rat received freshly harvested cells.

Immunocytochemistry: assessment of cell purity. LP OECs. To assess cell purity and to ensure that cells express typical morphology and phenotype before transplantation, GFP ${ }^{+}$LP OECs were plated onto glass slides after the second subculture and fixed in $4 \%$ paraformaldehyde (PFA) after 2 DIV. Purity of the culture was assessed using the following primary antibodies incubated overnight at $4^{\circ} \mathrm{C}$ : rabbit anti-p75 (1:1000; Chemicon), anti-mouse $S 100 \beta$ (1:1000; Sigma), and anti-glial fibrillary acidic protein (GFAP) (1:750; DakoCytomation, Glostrup, Denmark). Slides were then incubated for $1 \mathrm{~h}$ at room temperature with Alexa 594 goat secondary antibodies (1:100; Jackson ImmunoResearch, Mississauga, Ontario, Canada) in $2 \%$ goat serum, followed by a 10 min incubation in $0.5 \mu \mathrm{g} / \mathrm{ml} \mathrm{4}$ ',6-diamidine-2-phenylindole dihydrochloride (DAPI) (Boehringer Mannheim, Mannheim, Germany), and coverslipped in Vectashield mounting media (Vector Laboratories).

$O B$ OECs. Initially, to determine the optimal time and antibody concentrations for immunopanning, OB OEC purity was assessed by plating different panning conditions onto glass slides as described above, staining with rabbit anti-p75 (1:1000; Chemicon), as well as secondary antibodies and DAPI as described above. DAPI nuclei were counted, as well as $\mathrm{p} 75^{+}$cells to assess for the enrichment of $\mathrm{p} 75^{+}$cells. After optimizing cell purification procedures, all OB OEC cell cultures were then subjected to the same slide generation after second subculture and immunocytochemistry as described above for LP OECs.

In vitro migration assays. LP or OB OECs cultured for the same DIV were harvested at passage 2 and plated onto Boyden chambers pretreated with PLL ( $50 \mu \mathrm{g} / \mathrm{ml}$ in borate buffer, $1 \mathrm{~h}$ at room temperature) or laminin $\left(1 \mu \mathrm{g} / \mathrm{ml}\right.$ in PBS, $1 \mathrm{~h}$ at $37^{\circ} \mathrm{C}$ ) in 24 -well plates at a density of 5000 cells/well. The main well contained 2.5\% FBS in DMEM/F-12. Cells migrated for $20 \mathrm{~h}$, the top sides of experimental transwells were then swabbed, both sides were swabbed for negative controls, and neither side was swabbed for positive controls. Transwells were fixed in $0.1 \%$ glutaraldehyde in 4\% PFA in PBS for $30 \mathrm{~min}$ at room temperature. Membranes were then stained with DAPI, mounted onto glass slides, coverslipped with Vectashield (Vector Laboratories), and $5 \times$ images were collected, encompassing the entire membrane. $\mathrm{DAPI}^{+}$nuclei were counted, and migration values were expressed as a percentage of total cells on positive membranes (experimental minus negative counts divided by the total cells on positive membranes).

Spinal cord injury and cell transplantation. Dorsolateral funiculus crush. Animal procedures were performed in accordance with the guidelines of the Canadian Council for Animal Care and were approved by the Animal Care Committee of the University of British Columbia. Forty-two adult male Sprague Dawley rats (150-200 g; Charles River Laboratories, Wilmington, MA) were immunosuppressed with cyclosporine A (10 $\mathrm{mg} \cdot \mathrm{kg}^{-1} \cdot \mathrm{d}^{-1}$, i.p.; Novartis Pharmaceuticals, Mississauga, Ontario, Canada) $2 \mathrm{~d}$ before surgery and each day for the duration of the experiment. After anaesthetization with xylazine/ketamine $(10$ and $70 \mathrm{mg} / \mathrm{kg}$, i.p.), a hemilaminectomy was performed, exposing the left halves of the third and fourth cervical segments. The dura was then cut with microscissors, exposing the spinal cord, and one prong of custom-designed fine surgical forceps was inserted between the gray and white matter, with the other prong outside the dorsolateral funiculus, to a depth of $1 \mathrm{~mm}$. The forceps were then closed for 18-20 s, crushing the dorsolateral funiculus. Previous studies in our laboratory have confirmed that this injury reliably severs all rubrospinal axons (Ramer et al., 2004). Crush treatment was performed blind, because animals were designated to cell transplantation and control groups after crush.

Cell transplantation. LP or OB OEC cell slurries in DMEM/F-12 were drawn into a pulled glass pipette with a diameter of $20 \mu \mathrm{m}$ in a Hamilton syringe. OECs were stereotaxically microinjected either (1) within the lesion site over three injection points, at a depth of $0.7,1.0$, and $1.5 \mathrm{~mm}$, dividing the cell suspension equally between these three points, or (2) 1 $\mathrm{mm}$ rostral and caudal $(\mathrm{R} / \mathrm{C})$ to the lesion site at a depth of 0.6 and 1.2 $\mathrm{mm}$, dividing the suspension equally between four points (diagrammed in supplemental Fig. 1, available at www.jneurosci.org as supplemental material). A total of $1.5 \mu \mathrm{l}$ of cell slurry was injected at a rate of 100 
$\mathrm{nl} / \mathrm{min}$, so that each rat received a total of $75,000-90,000$ cells. Control animals received the same volume of DMEM/F-12 injected at the same sites at the same rate. The glass pipette remained in place for $5 \mathrm{~min}$ after each injection to ensure that cells remained in the spinal cord and were not withdrawn with the syringe. After injection, the pipette was slowly pulled back, and the muscle and skin were closed with interrupted sutures. The $28 \mathrm{~d}$ survival groups were as follows: direct LP OEC, $n=5 ; \mathrm{R} / \mathrm{C}$ LP OEC, $n=4$; direct OB OEC, $n=4$; R/C OB OEC, $n=4$; direct control, $n=4$; and $\mathrm{R} / \mathrm{C}$ control, $n=4$. The $24 \mathrm{~h}$ survival groups were as follows: direct LP OEC, $n=3$; R/C LP OEC, $n=5$; R/C OB OEC, $n=4$; and $\mathrm{R} / \mathrm{C}$ control, $n=5$.

Immunohistochemistry. At $24 \mathrm{~h}$ or $28 \mathrm{~d}$ after SCI and transplantation, animals were killed with a lethal overdose of chloral hydrate $(100 \mathrm{mg} / \mathrm{kg}$, i.p.) and transcardially perfused with PBS, followed by $4 \%$ PFA, pH 7.4. Cervical spinal cords and brain were dissected, cryoprotected with successive sucrose sinking in 12, 18, and 24\% sucrose in PBS for $24 \mathrm{~h}$ each, followed by freezing in Tissue-Tek optimal cutting temperature compound (Sakura, Tokyo, Japan) in isopentane over dry ice. Sections of spinal cord were collected at $14 \mu \mathrm{m}$ and stored at $-20^{\circ} \mathrm{C}$. Standard immunohistochemical procedures used for most detection were as follows: sections were thawed and adhered to the slide by warming for 10 $\mathrm{min}$, followed by postfixation in $4 \%$ PFA for $10 \mathrm{~min}, 30 \mathrm{~min}$ of permeabilization in $0.01 \%$ Triton X-100, 20 min block in $4 \%$ normal goat serum in PBS, and incubation of primary antibody overnight at $4^{\circ} \mathrm{C}$ in $2 \%$ serum. The following primary antibodies were used against: GFAP (1:400; DakoCytomation), rabbit anti-p75 (1:500; Chemicon) S100 $\beta$ (1: 1000; Sigma), mouse anti-p75 (mp75) (1:50; Chemicon), rat endothelial cell antigen (RECA) (1:50; Serotec, Oxford, UK), laminin (1:1000; Sigma), neurofilament heavy chain (NF) (1:500; Serotec), tyrosine hydroxylase (TH) (1:250; Chemicon), substance P (subP) (1:1000; Chemicon), serotonin (5-HT) (1:8000; ImmunoStar, Hudson, WI), calcitonin gene-related peptide (CGRP) (1:200; Sigma), and streptomycin-cyanine 3 (1:250; Jackson ImmunoResearch). Secondary antibodies raised in goat and conjugated to Alexa 350, 488, or 594 were applied for $1 \mathrm{~h}$ at room temperature, and sections were then coverslipped in Vectashield (Vector Laboratories).

Image analysis and quantification. Z-stacked $200 \times$ or $100 \times$, montaged digital images were captured with an Axioplan 2 microscope (Zeiss, Jena, Germany), a digital camera (QImaging, Burnaby, British Columbia, Canada), and Northern Eclipse software (Empix Imaging, Mississauga, Ontario, Canada) and were processed using Northern Eclipse, Photoshop 7.0 (Adobe Systems, San Jose, CA), and SigmaScan Pro (SPSS, Chicago, IL) software. Lesion area and cavity size were quantified for each animal by outlining the lesion area defined by GFAP at three defined levels, $0.65,0.9$, and $1.15 \mathrm{~mm}$ ventral in the spinal cord, and calculating the total pixels in this area. GFAP immunodensitometry was performed on sections at $0.9 \mathrm{~mm}$ ventral for all animals in each treatment group and was quantified for a defined area size around the lesion site compared with the analogous area on the contralateral uninjured side of the spinal cord. Autofluorescent items were first removed by recoloring triplefluorescing items in black. All axon quantitation was performed at the three depths in the spinal cord named above Quantitation within the lesion site was performed by outlining the GFAP-reactive border, binning fluorescence from axon staining into four bins (to normalize staining between animals), and the number of pixels in the top three bins were counted. For areas on either side of the lesion site, defined selection areas measuring 750,000 pixels at 0.5 and $1 \mathrm{~mm}$ rostral/caudal to the rostra/ caudal lesion boundary were quantified as described for within lesion measured, by binning and counting pixels in the three top bins. A similar strategy was used to quantify $\mathrm{GFP}^{+}$items at locations within the lesion site, or 0.5 and $1 \mathrm{~mm}$ rostral and caudal to the lesion site. Items fluorescing in all three channels were colored black, and the number of GFP ${ }^{+}$ pixels were counted within selection areas measuring 750,000 pixels. Analysis of angiogenesis and directionality were performed using programs designed on Matlab (MathWorks, Natick, MA). Briefly, 100× montaged images stained with anti-RECA were automatically posterized to two levels, blood vessels above a threshold size were recursively mapped and counted, and a best-fit line was applied. Intersection points from lines were then mapped onto the same $x-y$ plane as the original
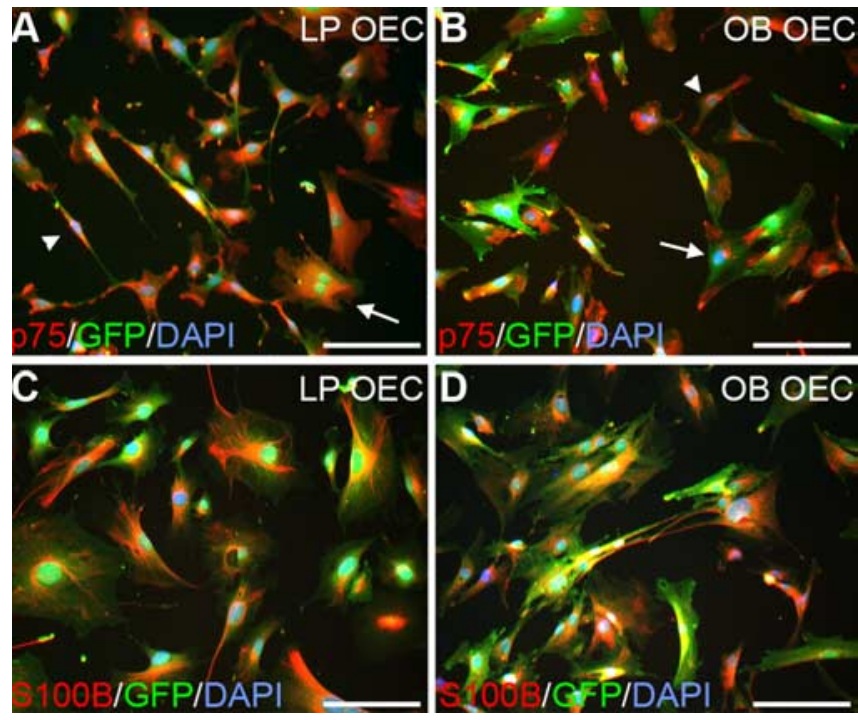

Figure 1. $\quad \mathrm{LP}$ and $\mathrm{OB} O \mathrm{EC}$ s exhibit similar antigenic and morphological properties in vitro. After 14 DIV, GFP ${ }^{+} \mathrm{LP}(\boldsymbol{A})$ and $\mathrm{OB}(\boldsymbol{B}) 0 \mathrm{ECS}$ express $\mathrm{p} 75$ and $\mathrm{S} 100 \beta(\boldsymbol{C}, \boldsymbol{D})$ and have primarily a flattened (arrow) morphology, with some fusiform cells (arrowhead) present. Scale bars, $100 \mu \mathrm{m}$.

image, and the number of intersection points in the lesion site, as defined by an outline of the GFAP scar, was assessed. The scar area was then moved randomly and automatically around the image 100 times to ascertain a baseline value of directionality. The ratio of directionality in the lesion and at the random points is reported. $t$ tests were used when appropriate, or ANOVAs followed by post hoc analysis using Tukey's tests were used to compare across groups. Graphical data are presented with error bars representing SEM.

\section{Results}

To assess their comparative ability to promote regeneration, OECs were purified from the LP or OB of postnatal day 5 mice homozygous for eGFP under the $\beta$-actin promoter (RamonCueto and Nieto-Sampedro, 1994; Au and Roskams, 2003). LP (Fig. $1 A, C$ ) and OB (Fig. $1 B, D$ ) OECs grown for 14 DIV demonstrated similar morphologic and antigenic profiles for $\mathrm{S} 100 \beta$, GFAP, and the p75 neurotrophin receptor. LP and OB OECs exhibited both flattened and fusiform morphologies (Fig. 1A,B). OB OECs demonstrated a broader range of p75 expression than LP OECs; some OB OECs were highly p75 positive, whereas the majority demonstrated low p75 levels (Fig. 1B). Despite their antigenic similarity, LP OECs demonstrated a threefold higher expansion rate than $\mathrm{OB}$ OECs from passage 1-2 under the same culture conditions.

Purified passage $2 \mathrm{eGFP}^{+} \mathrm{LP}$ and OB OECs cultured for 14 DIV were transplanted either directly into or at sites $1 \mathrm{~mm}$ rostral and caudal to a crush of the dorsolateral funiculus. We first addressed differences between LP and OB OECs that may be predicted based on their home environments in the PNS and CNS compartments of the olfactory system such as their ability to migrate within the CNS and preferential interactions with endogenous glia. We tested whether R/C-transplanted LP and OB OECs displayed different patterns of migration within the CNS by assessing their change in distribution from $24 \mathrm{~h}$ to $28 \mathrm{~d}$ after lesion (Fig. 2). At $24 \mathrm{~h}$ after injection, $25 \pm 7.7 \%$ of all transplanted LP OECs and $30 \pm 6.9 \%$ of OB OECs were already found at the lesion site, and both types of OECs were similarly arranged in a stream from the rostral injection point to lesion center. Because we could not detect cells between the caudal injection point 

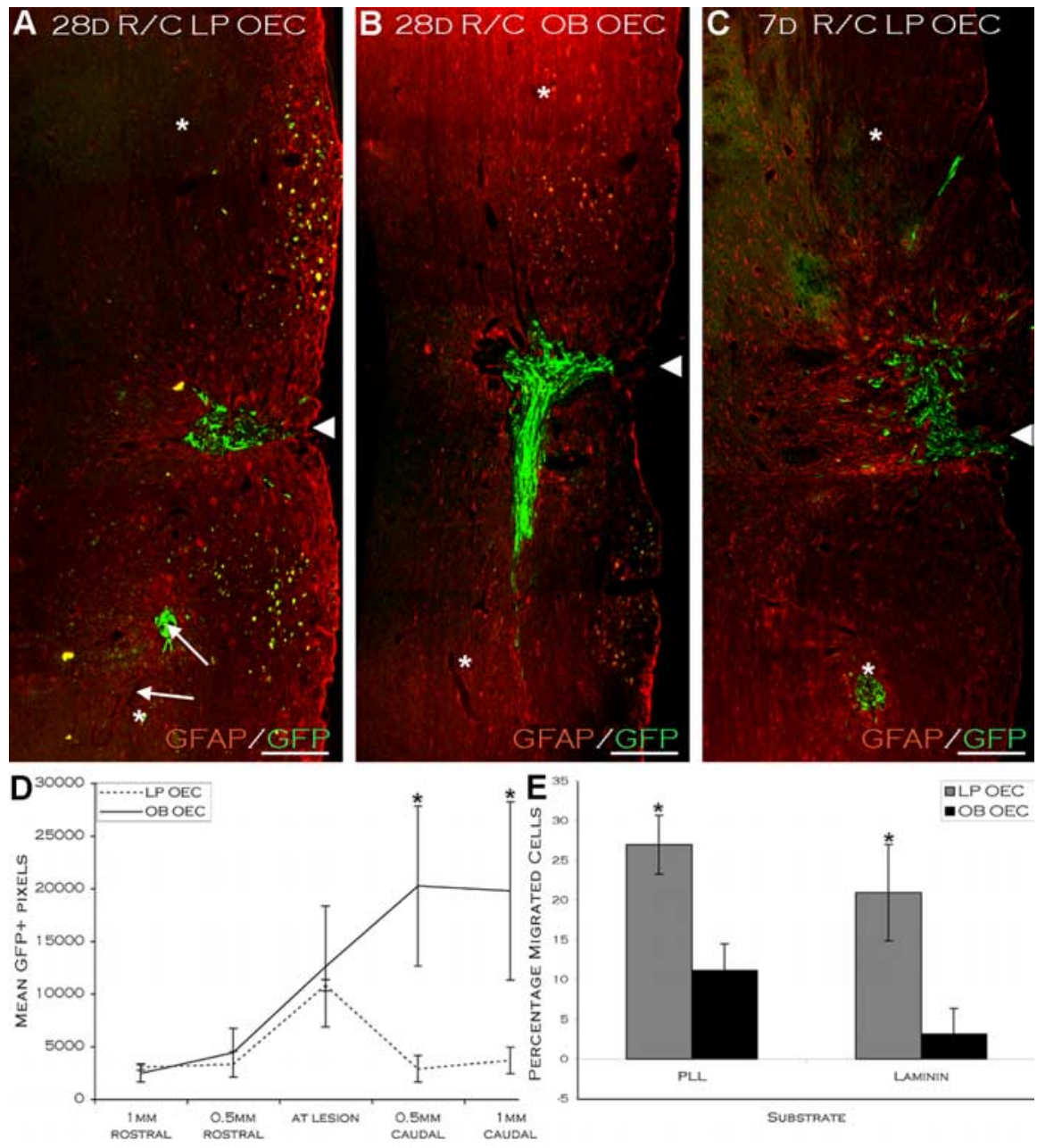

Figure 2. $\quad \mathrm{LPOECS}$ and $\mathrm{OB} O \mathrm{EC}$ s differ in their ability to migrate in vivo and in vitro. At $28 \mathrm{~d}$ after lesion, $\mathrm{R} / \mathrm{C}$ transplanted GFP + LPOECs ( $\boldsymbol{A})$ migrate from their injection points (asterisk) to occupy the lesion site (arrowhead), denoted by GFAP immunoreaction (red pseudocolor), whereas $\mathrm{R} / \mathrm{C}$ transplanted GFP ${ }^{+} \mathrm{OB} O \mathrm{OCS}(\boldsymbol{B})$ are visible between injection points and lesion site $(n=4$ of 4 animals with surviving GFP ${ }^{+}$cells). The larger area occupied by OB OECs (B) resembles migrating R/C LP OECS at $7 \mathrm{~d}(\boldsymbol{C})$. D, Quantitative assessment of GFP ${ }^{+} \mathrm{LP}_{\text {and } O B} \mathrm{OECS}$ (in pixels) at 1 and $0.5 \mathrm{~mm}$ rostral/caudal and within the lesion site reveals significantly more GFP ${ }^{+}$cells at 0.5 and $1 \mathrm{~mm}$ caudal in $\mathrm{OB}$-treated rats than in LP OEC-treated rats $(p \leq 0.05)$. $E$, In vitro, using a Boyden chamber migration assay, OB OECs migrate $60 \%$ less than LP OECs after $20 \mathrm{~h}$ on PLL, and the migratory difference is exacerbated on laminin with $O B O E C s$ migrating $85 \%$ less than $\mathrm{LP} O \mathrm{ECS}(n=3 ; p \leq 0.02$, all groups). Data are presented as mean \pm SEM. Scale bars, $250 \mu \mathrm{m}$.

(which retained $42 \pm 10.6 \%$ of total LP-OECs and $28 \pm 6.2 \% \mathrm{OB}$ OECs transplanted) and lesion site (in four of five LP and three of four OB-transplanted rats), this suggests that fluid pressure may initially displace a subset of OECs from their rostral but not their caudal injection point. Migration of $\mathrm{GFP}^{+}$OECs from the caudal injection point to the lesion site was visible by $28 \mathrm{~d}$ in LP- and $\mathrm{OB}$-transplanted rats with surviving $\mathrm{GFP}^{+} \mathrm{OEC}$ (three of four LP and four of four OB) (Fig. 2A,B). However, the frequency and distribution of OECs between the injection and the lesion sites differed significantly between OEC types $(n=3,4 ; p \leq 0.05)$. Rostrocaudally transplanted rats had more $\mathrm{GFP}^{+}$OECs at $28 \mathrm{~d}$ than directly transplanted rats (0 of 5 LP OECs; one of four OB OECs). By quantifying $\mathrm{GFP}^{+} \mathrm{OEC}$ distribution, $\sim 45 \%$ of surviving $\mathrm{GFP}^{+} \mathrm{OB}$ OECs in rostrocaudally transplanted rats were still found between the caudal injection point and lesion site $(n=4)$ (Fig. 2D), similar to the distribution of LP OECs $7 \mathrm{~d}$ after injury and rostrocaudal transplantation (Fig. 3C). In contrast, at $28 \mathrm{~d}$, only $\sim 6 \%$ of surviving LP OECs remained near the caudal injec- tion point (Fig. $2 \mathrm{~A}$ ), with $51 \%$ of surviving $\mathrm{GFP}^{+}$cells found within the lesion site.

To further address whether migratory differences in vivo represented intrinsic differences in migratory ability of LP and OB OECs, a Boyden chamber assay was used. Cells plated onto a porous membrane coated with poly-L-lysine (normal OEC substrate) or laminin (rich at the lesion site) (Ramer et al., 2004b) were allowed to passively migrate through the membrane, and the ratios of migratory versus nonmigratory cells were assayed. At $20 \mathrm{~h}$, a significantly greater number of LP OECs migrated than OB OECs on PLL $(n=3 ; p \leq 0.02)$, and this effect was augmented on laminin $(n=3 ; p \leq 0.02)$, in which $85 \%$ fewer OB OECs migrated (Fig. $2 E$ ). These data suggest that, in vivo and in vitro, LP OECs migrate more readily than OB OECs.

\section{Lesion site area and cavity formation are decreased by $L P$ versus $O B$ OEC transplantation}

Differences in migratory ability may change how effectively LP and OB OECs are able to minimize lesion and cavity formation during the acute phase of SCI. To test whether differential migration correlated with lesion size, we used the GFAPreactive border as a marker of the perimeter of the lesion area and measured lesion area, cavity area, and the percentage of the lesion site occupied by cavity (Fig. 3A). All groups exhibited an easily defined lesion area containing some evidence of a cavity. However, rats that received direct $\mathrm{OB}$ OEC transplants (Fig. 3A) had a significantly increased lesion site area (by approximately twofold to threefold) compared with rats that received the same cells rostrocaudally (Fig. $3 B$ ) or with rats that received LP OECs transplanted either directly (Fig. $3 C$ ) or rostrocaudally ( $n=4$ all groups; $p \leq 0.02$ ) (Fig. 3D). Rats that received direct or rostrocaudally transplanted LP OECs also developed smaller cavities than rats with direct OB OEC transplants $(n=5$, 4,$4 ; p \leq 0.02$ and 0.04 , respectively) (Fig. $3 F$ ). The greatest significant decrease in cavity formation was in rats that received LP OECs transplanted rostrocaudally (Fig. $3 F$ ), which also resulted in a significantly lower percentage of the lesion site occupied by cavity (Fig. 3G), a trend not observed after rostrocaudal OB OEC transplantation (Fig. 3G). The smaller lesion site area in rostrocaudally transplanted LP and OB OEC rats and directly transplanted LP OEC rats was four times smaller than that seen in control animals, which also developed cavities an average of 46 times larger ( $p \leq 0.01$, all groups) than transplanted rats, occupying $93 \pm 3.3 \%$ of the lesion site.

\section{Reactive astrogliosis is reduced by} rostrocaudal transplantation

The physical barrier of the lesion site and cavity are major obstacles to axonal regeneration (Schwab, 2002). However, the astro- 

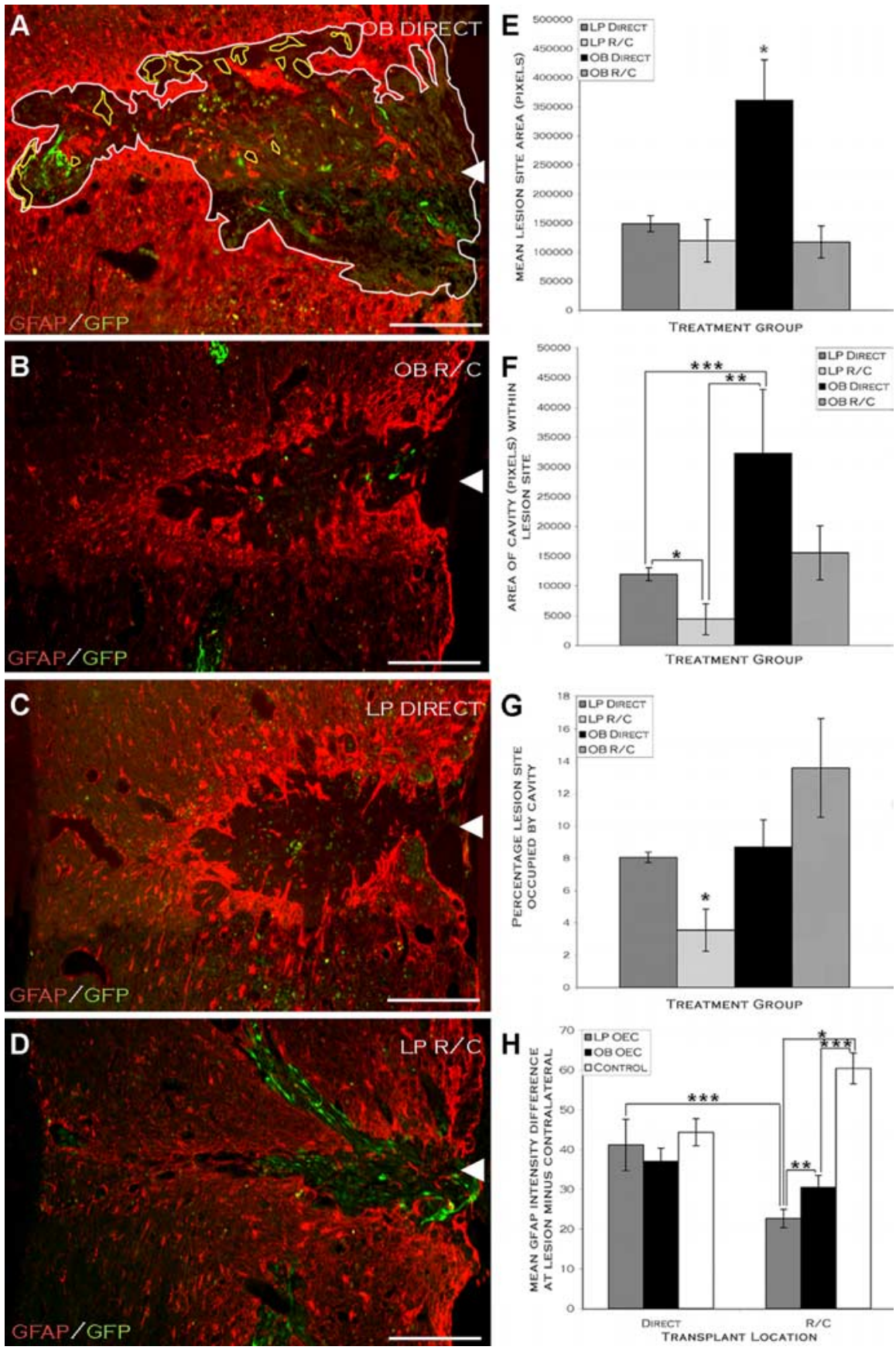

Figure 3. Lesion site area and cavity formation are decreased in LP-versus OB-treated rats. Astrogliosis is increased by direct transplantation. Examples of the lesion site area, visualized by anti-GFAP (red pseudocolor) and cavities $28 \mathrm{~d}$ after transplantation of GFP ${ }^{+}$OB OECs directly $(\boldsymbol{A})$ and rostrocaudally $(\boldsymbol{B})$ or GFP ${ }^{+} \mathrm{LPOECs}$ directly $(\boldsymbol{C})$ and rostrocaudally $(\boldsymbol{D})$. $\boldsymbol{A}$, Exemplar of quantitation to assess lesion site area (white line) and cavity formation (yellow line). $\boldsymbol{E}$, Area of the lesion site is significantly increased in direct $\mathrm{OB}$-treated rats compared with all other groups $(n=4 ; p \leq 0.05)$. $\boldsymbol{F}$, The area of cavity formed in direct $0 \mathrm{~B}$ is significantly greater than LP direct and LP R/C rats $(n=4 ; p \leq 0.05$ and $p \leq 0.05)$. The area of cavity is decreased by rostrocaudal transplantation, with $\mathrm{R} / \mathrm{C}$ LP OEC transplantation significantly reducing cavity formation compared with all groups $(n=4 ; p \leq$ 0.05). G, R/C LP OEC rats also have the smallest percentage of the lesion site with cavity $(n=4 ; p \leq 0.05)$. Astrogliosis as measured by GFAP intensity in a defined area around the lesion site normalized to GFAP on the contralateral side shows significantly decreased reactivity at the lesion site in rostrocaudally $(\boldsymbol{B}, \boldsymbol{D})$ versus directly $(\boldsymbol{A}, \boldsymbol{C})$ transplanted rats compared with control rats. Furthermore, rostrocaudal LP OEC transplantation results in an additional significant reduction in GFAP intensity compared with rostrocaudal OB OEC transplantation ( $n=4$ for all groups except LP direct, $n=5$; ${ }^{*} p \leq 0.001,{ }^{* *} p \leq 0.05,{ }^{* * *} p \leq 0.01$ ). Data are presented as mean \pm SEM. Scale bars, $250 \mu \mathrm{m}$.

cytic scar, produced by reactive astrocytes, contains growthinhibitory molecules that form an additional chemical obstacle to growing axons (Moreau-Fauvarque et al., 2003; Camand et al.,
2004). Because both the OEC type and method of introduction significantly altered the lesion site and cavity area, we hypothesized that inhibitory astrogliosis might occur differentially between treatment groups. All groups were tested for the distribution of GFAP-expressing astrocytes (Fig. 3A-D). The intensity of GFAP immunoreactivity surrounding and including the lesion site was normalized to an equally sized defined area of GFAP immunoreactivity contralateral to the lesion site. This controlled for between-animal differences in baseline reactivity and background staining. Direct transplantation of $\mathrm{LP}$ and OB OECs produced a reactive astrogliosis similar in extent to direct injection of media (Fig. $3 A, C, H$ ). In contrast, rostrocaudal injection of media stimulated the most extensive astrogliosis of all treatment groups, a reaction that was significantly lowered by transplantation of both OEC types rostral and caudal to the lesion $(n=4,4,4 ; \mathrm{LP}, p \leq 0.001 ; \mathrm{OB}, p \leq 0.01)$. Rostrocaudal transplantation of both LP and OB OECs also significantly decreased GFAP intensity compared with direct transplantation, with rostrocaudal LP OEC transplantation lessening GFAP reactivity to the greatest extent $(n=4,4,5,4$, $4,4 ; p \leq 0.05)$ (Fig. $3 H$ ). The reduced astrocytic reaction observed in rostrocaudal versus direct transplanted rats suggests that this method of transplantation may create a more permissive environment for axon extension (Lakatos et al., 2003), although no additional decrease was observed in CSPG expression between treated groups (data not shown) over that reported previously (Ramer et al., 2004b).

\section{LP and OB OECs similarly recruit endogenous Schwann cells to the lesion site}

Interactions between OECs and glia other than astrocytes could also significantly affect regeneration outcomes. Schwann cells (SCs) are highly permissive for regeneration and have been widely used for their ability to promote regeneration and remyelination after CNS lesions (Bunge, 2002). We have suggested previously that part of the mechanism whereby OECs may stimulate regeneration may be their ability to promote the infiltration of endogenous SCs into the spinal cord (Ramer et al., 2004b). However, we do not know whether OB OECs also promote SC infiltration in this lesion paradigm. Immunostaining of all groups for the rat-specific low-affinity nerve growth factor receptor mp75 compared with GFAP and $\mathrm{GFP}^{+}$OECs revealed endogenous cells expressing p75 in areas with OECs within the lesion site (Fig. $4 B, D$ ) and, less 

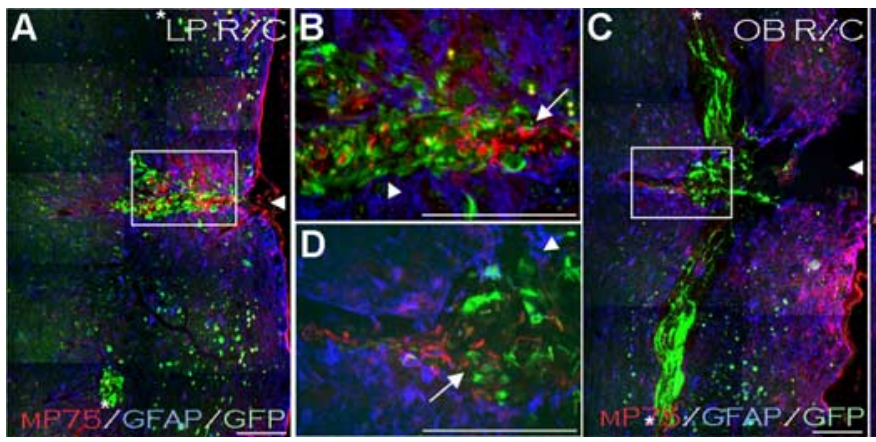

Figure 4. OEC interactions with endogenous glia: LP and OB OECs promote Schwann cell infiltration. Rat-specific $\mathrm{p} 75$ positive (red) endogenous $S$ chwann cells infiltrate the lesion site in $L P$-treated $(A)$ and $O B$-treated $(C)$ rats, associating closely with both $L P$ OECs ( $\boldsymbol{B}$, arrow) and OB OECs ( $\boldsymbol{D}$, arrow), as well as with astrocytes (GFAP; blue, arrowhead). Scale bars, $250 \mu \mathrm{m}$.
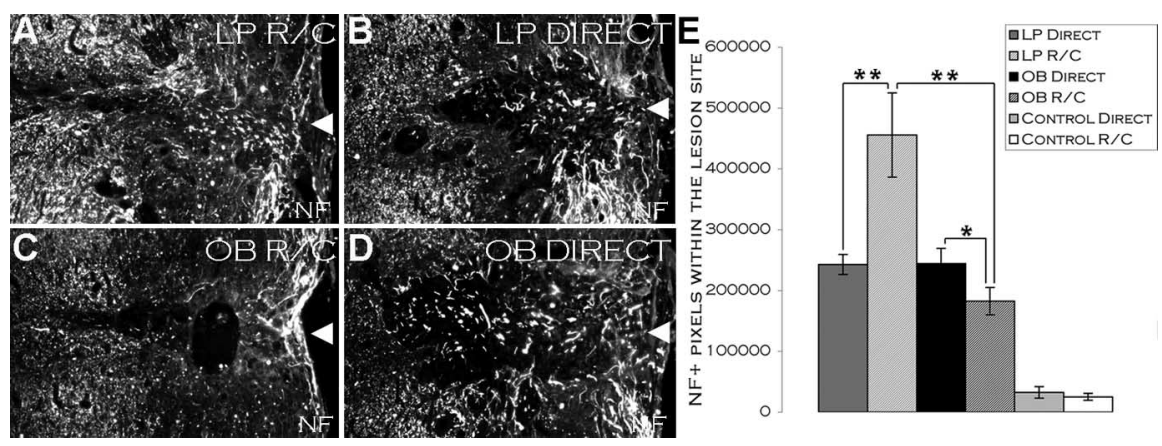

Figure 5. Neurofilament-positive axon sprouting into the lesion site is highly promoted by rostrocaudal LP OEC transplantation. OB R/C transplantation (C) results in fewer NF-positive axons sprouting into the lesion site (arrowhead) compared with OB direct $(\boldsymbol{D}), \mathrm{LPR} / \mathrm{C}(\boldsymbol{A})$ or direct $(\boldsymbol{B})$ transplantation. $\boldsymbol{E}$, Fluorescence densitometry for NF-positive pixels within the lesion site, as determined by outlining the GFAP-reactive border, reveals significantly greater NF-positive reactivity within the lesion site in all treated groups compared with control groups ( $p \leq 0.01$, all groups). Reactivity was also significantly greater in LPR/C transplanted rats compared with $\mathrm{LP}$ direct and $\mathrm{OB} \mathrm{R} / \mathrm{C}$ and $\mathrm{OB}$ direct rats $(n=4,5,4,4 ; p \leq 0.001$ all groups). Furthermore, for $0 \mathrm{~B} 0 \mathrm{EC}$ transplanted rats, there are significantly greater NF-positive pixels in the lesion site in direct versus $\mathrm{R} / \mathrm{C}$ rats $(n=4 ; p \leq 0.05)$. Data are presented as mean \pm SEM. Scale bars, $100 \mu \mathrm{m}$.

frequently, at the injection points in LP- (Fig. 4A) and OBtreated rats (Fig. $4 C$ ). We have identified previously these rat p75 ${ }^{+}$cells as SCs using other markers for rat SCs (Chernousov et al., 1999; Ramer et al., 2004b). Ingression of Schwann cells into the spinal cord parenchyma (measured from the GFAP lesion boundary) was more extensive in both OEC-treated groups, in which Schwann cells were found maximally at $350 \mu \mathrm{m}$ from the lesion site. Schwann cell infiltration was rarely seen in control animals (Fig. $4 E$ ) and did not penetrate beyond $80 \mu \mathrm{m}$ of the lesion boundary. SCs that infiltrated after OEC transplantation associated similarly with LP (Fig. $4 B$ ) and OB (Fig. 4C) OECs, as well as with CNS astrocytes (Fig. $4 B, D$ ). This suggests that some of the proregenerative effects of LP and OB OEC transplantation may be attributable, in part, to their ability to recruit, activate, or cooperate with endogenous Schwann cells.

\section{Axonal sprouting into the lesion site is increased in rats transplanted rostrocaudally with LP OEC animals}

The results so far suggest distinct biological differences in the ability of OB and LP OECs to promote repair. We next extended these findings to specifically test (1) differences in axonal outgrowth, (2) differences in angiogenesis, and (3) differences in the directionality of these parameters in relation to transplanted cells. This would allow us to establish whether secreted factors released into an SCI lesion area may uniformly promote repair

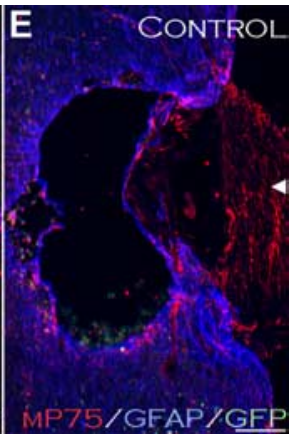

throughout the lesion site or whether the location of the OECs could directly change repair and regeneration parameters.

Large-caliber axons expressing NF demonstrated differences in degree of sprouting depending on both whether LP (Fig. $5 A, B$ ) or $\mathrm{OB}$ (Fig. 5C,D) OECs were transplanted and whether introduction was direct or rostrocaudal. In all animals, some axons sprouted into cavity-free areas of the lesion site, regardless of cell delivery approach, but the distribution of axon growth appeared to differ between treatment groups, in particular, within the lesion site. In rats that received direct transplants of LP and OB OECs, axonal growth was essentially stalled at the caudal lesion boundary (four of four for each group) (Fig. $5 B, D$ ). In addition, although some $\mathrm{NF}^{+}$axons were visible within the lesion site in both direct transplant groups, zones devoid of $\mathrm{NF}^{+}$axons were apparent, adjacent to the GFAP-immunoreactive border (LP direct, $n=3$ of 4 ; OB direct, $n=4$ of 4). Rats that received rostrocaudal LP OEC transplants (Fig. 5A) demonstrated a higher incidence of $\mathrm{NF}^{+}$axons within the lesion site compared with all other groups. Furthermore, $\mathrm{NF}^{+}$reactivity appeared uniform throughout the lesion site, including at the astrocytic border, compared with rats that received $\mathrm{LP}$ or OB OECs transplanted directly into the lesion. Rats that received rostrocaudal OB OEC transplants demonstrated the lowest incidence of $\mathrm{NF}^{+}$reactivity within the lesion site ( $n=4$ of 4 ) (Fig. 5C). To quantitatively assess the differences in axon growth within the lesion site in all treatment groups, densitometry of $\mathrm{NF}^{+}$pixels was performed by outlining the GFAP-reactive border and counting $\mathrm{NF}^{+}$pixels within this area (Fig. 5E). A significant increase in growth within the lesion was promoted by rostrocaudal transplantation of LP OECs compared with all other groups ( $n=4 ; p \leq 0.001$, all groups) (Fig. $5 E$ ). However, rats that received $\mathrm{OB}$ OECs directly at the lesion site demonstrated significantly more $\mathrm{NF}^{+}$axons within the lesion compared with rostrocaudal OB OEC transplants $(n=4$, all groups; $p \leq 0.05)$. These results suggest that cell type and delivery method differentially influenced the pattern of growth of sprouting axons and also affected their ability to penetrate the lesion site.

\section{Directional angiogenesis is enhanced by OEC treatment}

Much of the axonal outgrowth reported above, particularly in rats treated by rostrocaudal LP OEC transplantation (Fig. 5A), appeared directed toward the lesion site. We have shown previously that angiogenesis in the lesion site occurs after LP OEC transplantation, and that many axons extend along blood vessel laminas (Ramer et al., 2004b). Furthermore, an angiogenic response correlated with axon growth has also been demonstrated after contusive injury (Loy et al., 2002). Therefore, it is possible that the direction of axon growth may be related to the direction of blood vessel growth, and this could determine whether different transplantation strategies could be used to encourage sprout- 

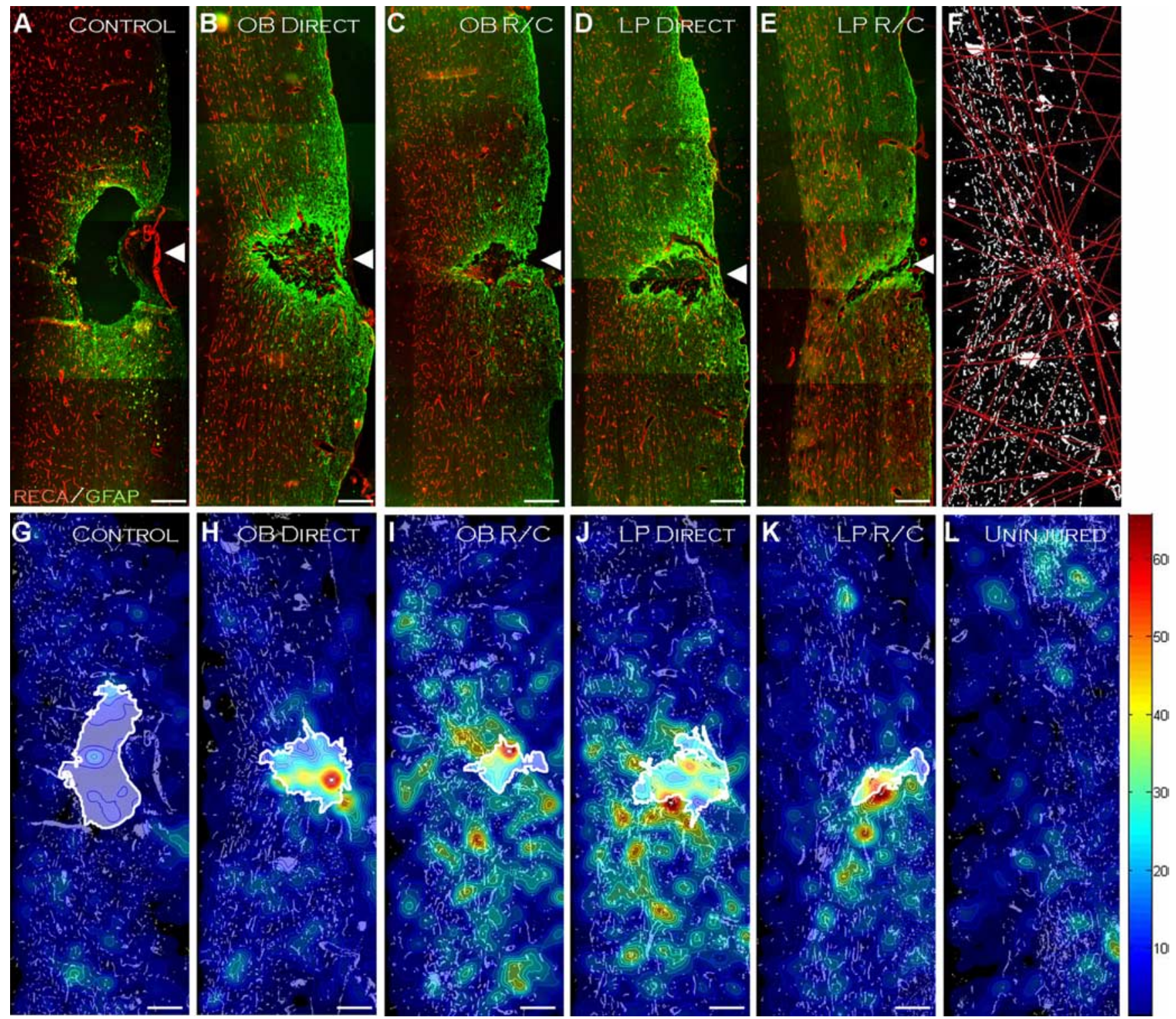

Figure 6. $L P$ and $O B O E C$ s promote directional angiogenesis. Angiogenesis, as recognized by anti-RECA immunoreaction (red), is induced at the lesion site (arrowhead) in $O B$ direct $(B)$ and $R / C$ $(\boldsymbol{C})$ and $L$ P direct $(\boldsymbol{D})$ and $R / C(\boldsymbol{E})$ rats. $\boldsymbol{F}$, Directionality was assessed by constructing best-fit lines to $R E C A$-positive structures and assigning normal distributions to each intersection point to determine a contour map of intersection points. Contour maps for control $(\boldsymbol{G}), 0 B$ direct $(\boldsymbol{H}), 0 B R / C(\boldsymbol{I}), \mathrm{LP}$ direct $(\boldsymbol{J})$, and $L P R / C(\boldsymbol{K})$ show the number of intersections in a given area, as indicated in the color scale bar. The height of the contour map in $\mathbf{G}-\boldsymbol{K}$ falling within the lesion site (white outlines in $\mathbf{G}-\boldsymbol{K}$ ), as indicated by anti-GFAP (green pseudocolor), was compared with the height falling within the same area randomly placed 100 times throughout the image to produce a directionality quotient. Directionality quotients and total number of blood vessels, normalized for tissue area, are presented in Table 1. Scale bars, $250 \mu \mathrm{m}$.

ing axons to extend longitudinally down the spinal cord instead of becoming entangled at the lesion site. To assess the extent and directionality of blood vessel growth, anti-RECA and GFAP detection was used to visualize blood vessels around and within the lesion site (Fig. 6A-E). To analyze directionality, montages of Z-stacked images of RECA-immunoreactive endothelia were assigned a threshold intensity (applied within and across groups), counted, and assigned a best-fit line along their linear axis, using an algorithm programmed in Matlab, to determine their direction of growth (Fig. $6 F$ ). The predicted intersection points of lines were then summed to produce contour maps of most likely endothelial convergence (Fig. $6 G-K$ ). The density of intersections within the lesion site was normalized to a baseline of intersections within the same lesion area, randomly placed throughout the same spinal cord. This provided a measure of the extent of directionality of blood vessels toward the lesion site, normalized for lesion area and for number of blood vessels. Scores greater than zero therefore indicate directionality of blood vessels toward the lesion site. In all OEC-treated rats, there were significantly greater numbers of blood vessels than in control animals (Table 1 ). As well, there was a significant and $>1.9$-fold increase in directionality of blood vessel growth toward the lesion site in rats that received OEC transplants compared with the random endothelial growth in control animals (Table 1). Rats that were directly transplanted with OB OECs demonstrated the most significant blood vessel growth directly toward the lesion site. Vascularization and enhanced regeneration have been tightly linked in the peripheral nervous system (Hobson et al., 2000), and the increase in blood vessels and their direction of growth in all OEC-treated rats may favor directed axon growth within the CNS. 
Table 1. Quantification of blood vessel number and direction after OEC transplantation

\begin{tabular}{cccc}
\hline & $\begin{array}{l}\text { Mean number } \\
\text { ofblood vessels }\end{array}$ & Directionality quotient & $\begin{array}{l}\text { Fold increase in } \\
\text { directionality over control }\end{array}$ \\
\hline Control & $209 \pm 23.91$ & $-0.0287 \pm 0.0207$ & \\
OB direct & $302 \pm 44.66$ & $0.0767 \pm 0.0243$ & 3.6 \\
OB R/C & $356 \pm 22.71$ & $0.0082 \pm 0.0078$ & 1.9 \\
LP direct & $336 \pm 38.77$ & $0.0165 \pm 0.0066$ & 2.1 \\
LP R/C & $368 \pm 36.28$ & $0.0233 \pm 0.010$ & 2.3 \\
\hline
\end{tabular}

$\mathrm{OEC}$ transplantation enhances angiogenesis and directs blood vessels toward cell-rich areas. Quantification of blood vessel number for control and treated groups and directionality quotients for all groups toward the lesion site were performed using Matlab programming.
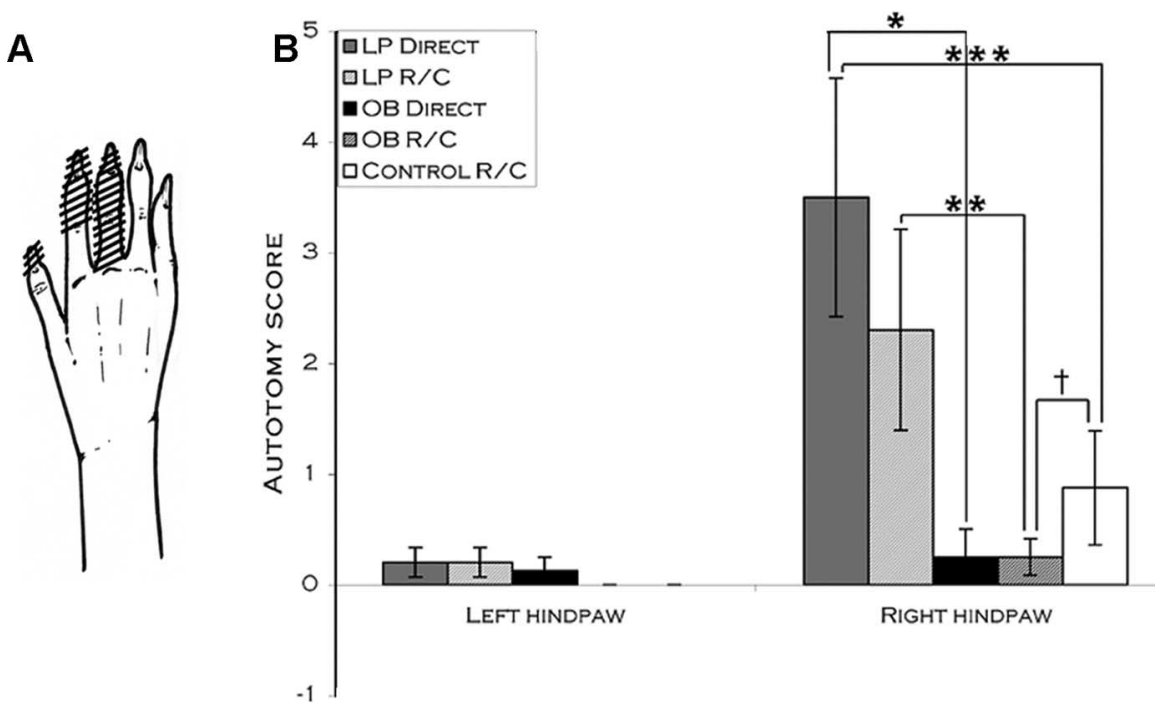

Figure 7. Autotomy is reduced by $O B O E C$ transplantation but elevated by LP OEC transplantation. $\boldsymbol{A}$, Schematic of scoring system for autotomy; from left to right, scores would be assigned as 1, 2, and 3, respectively. $\boldsymbol{B}$, Direct LP OEC-treated rats show significantly greater autotomy than direct $\mathrm{OB} \mathrm{OEC}$-transplanted rats and control rats $\left(n=5,4,5 ;{ }^{*} p \leq 0.01,{ }^{* * *} p \leq 0.05\right)$. R/C LPOEC rats exhibit significantly increased autotomy compared with $\mathrm{R} / \mathrm{COB} 0 \mathrm{E}$-transplanted rats $\left(n=4,4 ;{ }^{* *} p \leq 0.05\right)$, but they do not differ significantly from control rats. $R / C O B$ rats showed significantly decreased autotomy compared with control rats $(p \leq 0.05)$. Data are presented as mean \pm SEM.

\section{Autotomy is reduced by OB OEC but elevated by LP OEC transplantation}

Transplantation of either LP or OB OECs resulted in the enhanced growth of $\mathrm{NF}^{+}$axons within the lesion site; however, it is unclear whether these axons form functional connections, either appropriate or inappropriate, with target neurons. At $27 \mathrm{~d}$ after lesion and transplantation, autotomy was apparent in some rats, so we sought to determine whether the degree of autotomy varied between groups because this measure could serve as an admittedly negative behavioral readout for changes in functional connectivity. Autotomy is the self-attack of a (partially) denervated limb, characterized by excessive licking, grooming, and biting of the anesthetic limb, eventually resulting in digit amputation (Kauppila, 1998; Zimmermann, 2001). Autotomy was scored using the methods described by Wall (1979), in which a total of three points were awarded for the attack of each digit: 1 point for nail removal, 2 points for amputation up to the first knuckle, and 3 points for total digit removal, for a total of 15 possible points for each paw (Fig. 7A). For each rat, the affected right hindpaw was scored as well as the left hindpaw, which served as an internal control. Rats that received direct transplants of LP OECs $(n=4)$ had the greatest autotomy scores, significantly greater than either control $(n=4)$ or directly transplanted OB rats $(n=5 ; p \leq 0.05$ and $p \leq 0.01$ ) (Fig. $7 B$ ). Rostrocaudally transplanted OB OEC rats demonstrated lower autotomy than rostrocaudally transplanted LP rats and control rats $(n=4,5,5 ; p \leq 0.05$ and $p \leq$
0.05, respectively) (Fig. 7B). LP OEC transplantation thus increased autotomy regardless of injection paradigm, whereas the incidence $(\mathrm{OB}, 2$ of 8 rats; LP, 6 of 10 rats) and extent of autotomy ( $92 \%$ less autotomy in $\mathrm{OB}$ rats) was less in OB-treated rats.

\section{Sprouting of TH-, subP-, and CGRP- positive axons is differentially stimulated by LP or OB OEC transplantation}

To test whether LP and OB OECs may differentially stimulate axonal sprouting that could contribute to autotomy, we assayed the pattern of axon outgrowth from dorsal root afferents as well as different descending tracts. We have shown previously that LP OEC transplantation stimulates the growth of $5-\mathrm{HT}^{+}$and $\mathrm{TH}^{+}$axons, as well as some growth of dorsal root afferents expressing $\mathrm{CGRP}^{+}$or subP ${ }^{+}$(Ramer et al., 2004b). We assayed horizontal sections through the lesion site for the presence of these axonal subpopulations using the $\mathrm{GFAP}^{+}$border to identify the boundaries of the lesion site. Montaged, Z-stacked sections were assessed for the total number of positive pixels within the lesion site and within defined areas 0.5 and $1 \mathrm{~mm}$ rostral and caudal to the lesion.

We first tested for the presence of different axonal subtypes at $24 \mathrm{~h}$ after lesion and transplantation and found that all axons tested were absent from the lesion site and retracted substantially from the rostral and caudal lesion boundaries (supplemental Fig. 2, available at www.jneurosci.org as supplemental material). By $28 \mathrm{~d}$, in rats that received LP OECs (Fig. $8 A$ ) and OB OECs (Fig. $8 B$ ), subP-positive axons were found within the lesion site but were increased caudal to the lesion site. No significant differences in axonal outgrowth of subtypes were observed between direct and rostrocaudally transplanted rats within LP or OB OEC treatment groups, and both sets of data for each OEC subtype are presented collectively. In OB-transplanted rats, subP reactivity was found rostral to the lesion site (Fig. $8 B$, inset), whereas less reactivity was observed at this location in LP OEC (Fig. $8 \mathrm{~A}$, inset) transplanted rats. subP-positive axons were significantly increased at all points in rats that received OB OECs compared with LP OECs ( $n=4$ each group; $p \leq 0.05$ all levels) (Fig. $8 C$ ). This suggests that OB OECs are more effective than LP OECs at promoting the sprouting of subP-positive axons after injury.

CGRP-positive nociceptive/temperature responsive afferents are also responsive to LP OEC transplantation (Ramer et al., 2004b), and their sprouting could impact pain sensation after SCI (Jang et al., 2004). Detection of CGRP-positive axons in rats that received LP OECs (Fig. 8D) and OB OECs (Fig. 8E) revealed similar sprouting patterns between groups, although LP OECs slightly increased sprouting $0.5 \mathrm{~mm}$ rostral to the lesion site $(n=$ 4 each group) (Fig. $8 F$ ) and demonstrated increased sprouting at the rostral lesion border (Fig. $8 D$, inset, $F$ ). Both types of OEC did, however, promote the growth of CGRP-positive axons over 
control animals, particularly within the lesion site, in which no sparing of CGRPpositive axons was visible at $24 \mathrm{~h}$ after lesion. No significant differences in CGRPpositive sprouting were observed between direct and rostrocaudally transplanted rats.

Sprouting of raphespinal 5-HTpositive axons appeared similar in both LP- and OB-treated rats (Fig. 8G,H) and was extensive compared with $\mathrm{CGRP}^{+}$and subP $^{+}$sprouting; no significant differences were observed between transplant groups ( $n=4$ for all groups) (Fig. $8 I$ ). 5-HT-positive axons also appeared to diminish significantly slightly caudal to the lesion site (Fig. 8G,H, insets). In contrast, detection of $\mathrm{TH}$ revealed significantly more $\mathrm{TH}$-positive axons rostral to and within the lesion site in rats that received LP OECs compared with OB OECs (Fig. $8 \mathrm{~J}-L$ ). This was particularly visible at the rostral lesion boundary, in which $\mathrm{TH}$ positive axons were increased in LPtransplanted (Fig. 8J, inset) compared with OB-transplanted (Fig. $8 I$, inset) rats. Because neither 5-HT- nor TH-positive axons were present within the lesion site $24 \mathrm{~h}$ after lesion, the transplanted LP and OB OECs likely promote growth of these axon subtypes.

\section{Discussion}

OECs are currently considered prime candidates for cell-based therapies to repair the injured CNS (Lakatos and Franklin, 2002). Because some OB OEC transplantation experiments have indicated different degrees of functional recovery from SCI (Ramon-Cueto et al., 2000; KeyvanFouladi et al., 2003; Garcia-Alias et al., 2004), cell preparations containing LP OECs are currently being tested for treating human SCI based on the assumption that LP and OB OECs are functionally equivalent (Senior, 2002; Huang et al., 2003; Rabinovich et al., 2003). For both mechanistic and clinical reasons, we have compared the effect of transplanting OB and LP OECs into lesioned spinal cord and determined that they produce significantly different regeneration outcomes. Compared with OB OECs, LP OECs decrease lesion site and cavity area and increase sprouting of $\mathrm{NF}^{+}$and $\mathrm{TH}^{+}$axons but also stimulate autotomy. In contrast, OB OEC transplantation increases lesion site area and cavity formation, promotes sprouting of subP ${ }^{+}$axons, and promotes the greatest directional angiogenesis. In addition, rostrocaudal compared with direct transplantation suggests that LP and OB OECs have different abilities to migrate and that cell delivery method significantly affects astrogliosis, $\mathrm{NF}^{+}$sprouting, and cavity formation.
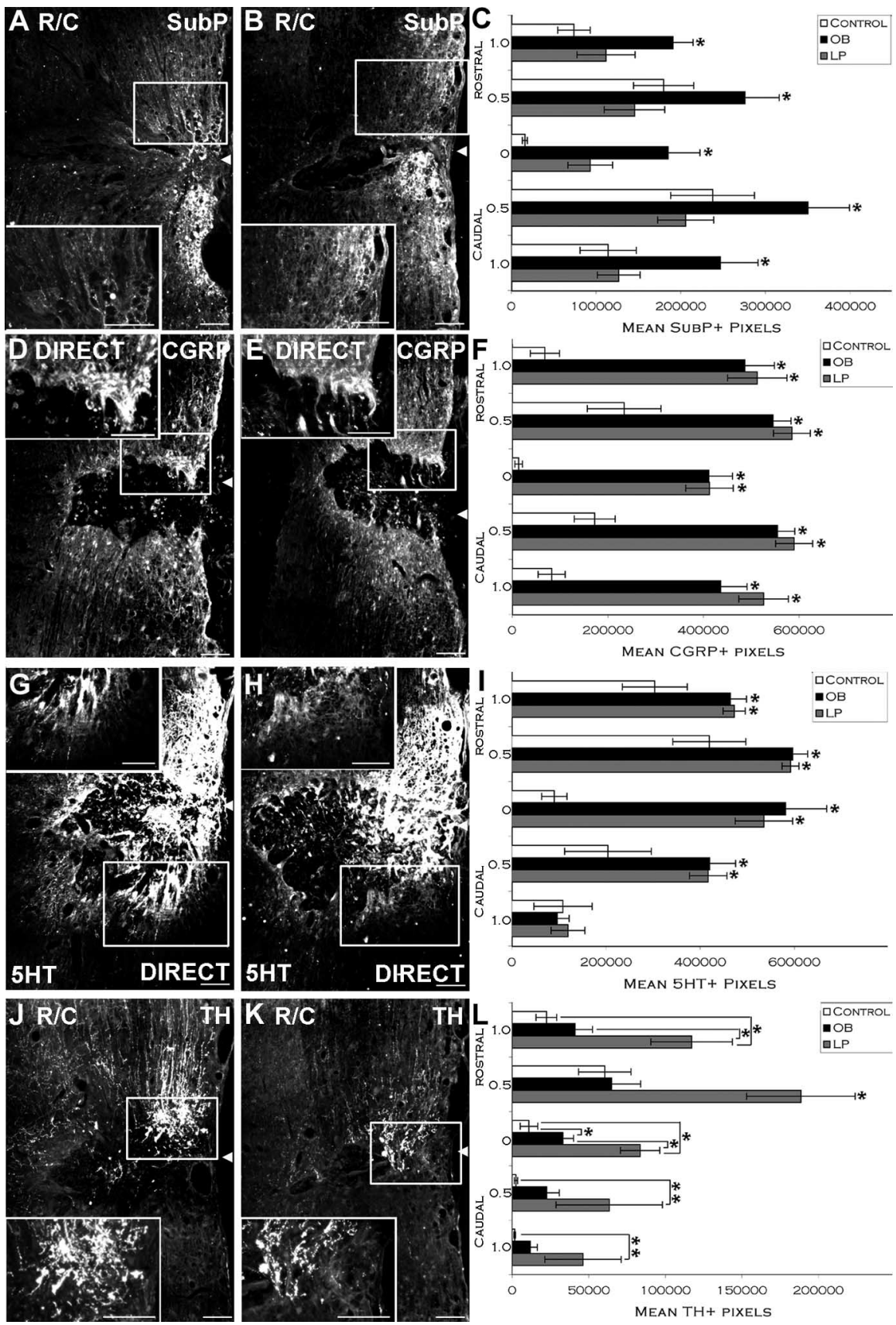

Figure 8. TH-positive and subP-positive axons are differentially responsive to $L P$ and $O B O E C$ transplantation. subP axons sprout less in response to $\mathrm{LP} O \mathrm{OEC}(\boldsymbol{A})$ than to OB OEC ( $\boldsymbol{B})$ transplantation. $C$, Quantification of subP-positive pixels by fluorescence densitometry shows significantly increased subP in $\mathrm{OB} O \mathrm{OEC}$ animals 1 and $0.5 \mathrm{~mm}$ rostral and caudal to the lesion site and within the lesion site compared with LP-treated rats $(n=9,8 ; p \leq 0.05$, all groups). CGRP-positive axons sprout in response to LP (D) and $\mathrm{OB}(\boldsymbol{E}) \mathrm{OEC}$ transplantation compared with control groups $(p \leq 0.001)$ but sprout significantly more $0.5 \mathrm{~mm}$ rostral to the lesion in $\mathrm{LP}$ than $\mathrm{OB}$ rats $(n=9,8 ; p \leq 0.05)(\boldsymbol{F})$. The quantity and distribution of sprouting 5 -HT-positive axons in $\mathrm{LP}(\boldsymbol{G})$ and $\mathrm{OB}$ $(\boldsymbol{H})$ OEC-treated rats is similar, with robust growth rostral to and within the lesion site $(\boldsymbol{I})$ compared with control animals ( $p \leq$ 0.05), but few axons penetrate caudal to the lesion $(\boldsymbol{G}, \boldsymbol{H}$, insets). TH axons respond more to LP OEC (J) than to OB OEC $(\boldsymbol{K})$ transplantation. $L$, TH growth, quantified by immunofluorescence densitometry, is significantly increased in $L P O E C-$ treated rats 1 and $0.5 \mathrm{~mm}$ rostral to and within the lesion site $(\boldsymbol{J}$, inset) compared with the same sites in OB OEC-treated rats and control rats $(\boldsymbol{K}$, inset) $(n=9,8,8 ; p \leq 0.001$ and $p \leq 0.001)$. All axons are white. Data are presented as mean \pm SEM. Scale bars, $100 \mu \mathrm{m}$.

The morphological and antigenic profiles of LP and OB OECs in culture (Fig. 1) suggest that both OEC types are very similar. However, their differing roles in PNS and CNS environments in the olfactory system, and expansion capacities in vitro, imply that LP and OB OECs should not be considered functional equals a priori and could behave differently after transplantation. Indeed, 
when transplanted rostrocaudally, LP and OB OECs were distributed differently $28 \mathrm{~d}$ after lesion: significantly more $\mathrm{GFP}^{+} \mathrm{LP}$ OECs had migrated into the lesion site, whereas GFP ${ }^{+}$OB OECs were located between the caudal injection point and lesion site (Fig. 2). This distribution could be explained by increased death of OB OECs at the lesion site or a greater loss of LP OECs at injection sites. The resemblance in cell distribution of $28 \mathrm{~d} \mathrm{R} / \mathrm{C}$ $\mathrm{OB}$ and $7 \mathrm{~d} \mathrm{R} / \mathrm{C}$ LP rats, coupled with the increased survival of $\mathrm{OB}$ OECs at $28 \mathrm{~d}$, suggests that the difference in cell distribution is primarily a result of intrinsic LP/OB OEC migration differences that resemble those we assayed in vitro (Fig. 2).

The ability of OECs to differentially migrate into a lesion site could have important consequences in SCI, because, in a dorsolateral funiculus lesion, a cavity forms at $24 \mathrm{~h}$ after injury when untreated (Ramer et al., 2004b). The greater percentage of cavity in rats that received rostrocaudal OB OEC transplants could thus simply be the result of a retarded migration of OB OECs (Fig. 3). The long-term presence of OECs at the lesion site appears to be a major determinant of reduced cavity size, because rostrocaudal LP OEC transplantation significantly reduced cavity formation compared with direct transplantation (in which fewer LP OECs survive) (Fig. 3).

The decreased lesion site area in rostrocaudally transplanted rats was further reflected in differences in astrocytic reactions after rostrocaudal versus direct transplantation. Increased GFAP reactivity around the lesion site of rats with direct versus rostrocaudal transplants of both OEC types suggests that LP and OB OECs may have similar interactions with astrocytes (Fig. 3). However, the increased GFAP immunoreactivity in rats that received transplants directly into the lesion site suggests that the acute presence of OECs within the lesion either enhances astrocyte division and/or exacerbates astrocytic hypertrophy (Fig. 3). Differences in astrogliosis could arise from (1) unfavorable interactions between OECs and astrocytes, (2) an increased local immune response after direct transplantation, or (3) a favorable interaction between OECs and astrocytes that requires long-term survival of OECs. Increased astrogliosis is unlikely caused by unfavorable OEC-astrocyte interactions, because astrocyte size, shape, and reactivity are not altered in vitro by contact with $\mathrm{OB}$ OECs (Lakatos et al., 2000, 2003). In addition, similar numbers of autofluorescent immune infiltrates were detected within the lesion site of rostrocaudally and directly transplanted animals (of the same cell type), arguing that the immune response may contribute to, but is not responsible for, increased astrogliosis in directly transplanted animals. Therefore, the decrease in GFAP intensity in rostrocaudally transplanted rats may be attributable to a favorable but necessarily prolonged interaction between OECs and astrocytes, because this delivery approach also promotes OEC survival. The association of OECs and astrocytes may synergize to reduce astrogliosis and create a more permissive environment, allowing SC infiltration and axonal extension. SC transplantation has promoted behavioral recovery from SCI (Pearse et al., 2004; Fouad et al., 2005); therefore, their infiltration after OEC transplantation could contribute to or potentiate regeneration regardless of OEC type.

Finally, functional assessments performed after OB OEC transplantation have focused primarily on positive outcome measures (Ramon-Cueto et al., 2000; Keyvan-Fouladi et al., 2003; Garcia-Alias et al., 2004), with the assumption that LP OECs would be similarly beneficial. The biological differences observed between LP and OB OECs in vitro (Fig. 2) and after direct and rostrocaudal transplantation (Figs. 2-4) suggest that there may be differences in how OEC type and transplantation approach affect axonal sprouting. Sprouting of $\mathrm{NF}^{+}$axons within the lesion site was greatest in rats that received rostrocaudal LP OEC transplants, with little axon density decrease across the lesion site (Fig. 5). In contrast, although direct transplantation of LP OECs was effective at drawing axons toward the lesion boundaries, fewer axons were able to penetrate the lesion/host interface. This effect could be a result of both trophic/tropic actions of OECs and changes to the permissiveness of the glial scar/lesion site, because rostrocaudal transplantation also decreased GFAP reactivity and cavity formation (Fig. 3). Therefore, permissiveness and trophic/ tropic actions may be maximized by rostrocaudal, but decreased by direct, LP OEC transplantation. However, if only the location of the cell transplant were responsible for differences in $\mathrm{NF}^{+}$ growth, then, based on evidence from LP OECs, one would expect (1) greater $\mathrm{NF}^{+}$axons within the lesion site in rats transplanted rostrocaudally than directly with OB OECs and (2) the same amount of $\mathrm{NF}^{+}$growth within the lesion site in rostrocaudal LP- and OB-treated rats. A comparison of only rostrocaudally transplanted LP and OB OEC rats shows that significantly greater $\mathrm{NF}^{+}$axons are present within the lesion in LP-treated rats (Fig. 5). This suggests that LP and OB OECs might secrete different neurotrophic factors and/or secrete them at different levels.

The significant increase in autotomy in LP OEC versus OB OEC transplant groups further underscores potential functional differences between these two cell types. Although the mechanisms of autotomy are not understood, autotomy is common after denervation or situations in which sensory modalities may be affected, as in our model. At present, it appears that OEC transplantation might have modified the sensory system by facilitating differential growth of different axonal populations or by differentially altering local circuitry. These possibilities imply that a higher degree of plasticity/remodeling may be induced by LP versus OB OECs, which could result in undesired effects. In comparison, recent work with transplanted embryonic stem cells into SCI has revealed the development of allodynia in addition to increased motor function, a feature not tested in most OEC transplantation studies (Hofstetter et al., 2005).

The differential sprouting of some axonal populations further implies that LP and OB OECs secrete different neurotrophic factors and therefore may differently promote recovery (Fig. 8): subP $^{+}$axons sprouted significantly more in OB- than LP-treated rats (Fig. 8). However, the most robust difference in sprouting was the growth of $\mathrm{TH}^{+}$neurons, whose growth was highly promoted by LP OEC transplantation (Fig. 8). Differences in the abilities of LP and OB OECs to promote axon elongation are in accord with their roles in the olfactory neuraxis. Furthermore, although OB OECs express NGF, BDNF, glial cell line-derived neurotrophic factor, artemin, and CNTF in vivo and in vitro (Woodhall et al., 2001; Lipson et al., 2003), their ability to promote outgrowth of peripheral ganglia and CNS explants as well as to promote sprouting within the spinal cord via secreted factors has been variable, whereas their ability to do so via direct cell-cell contact is greater (Sonigra et al., 1999; Lipson et al., 2003; Chuah et al., 2004).

Here, we present the first data directly comparing LP and OB OEC transplantation in a single SCI model and show that there are fundamental differences in intrinsic OEC properties that are retained after they are transplanted into lesioned spinal cord. These differences relate to (1) the ability to migrate and create a permissive regeneration-promoting environment at the lesion site and (2) differential outgrowth-promoting characteristics of LP and OB OECs. Although the maximal benefit to most regeneration parameters was achieved with rostrocaudal LP OEC 
transplantation, this is also associated with autotomy. This suggests that the vigorous sprouting associated with rostrocaudal LP OEC transplantation must be controlled so that appropriate connections are favored over inappropriate, and nearby uninjured tracts are not adversely affected. Thus, rostrocaudal LP OEC transplantation provides the greatest opportunity to promote regeneration or reconnect local circuitry after SCI, suggesting that LP OECs, combined with directed axon guidance stimulation, may merit additional development as a means to restore motor and sensory function after spinal cord lesion.

\section{References}

Au E, Roskams AJ (2003) Olfactory ensheathing cells of the lamina propria in vivo and in vitro. Glia 41:224-236.

$\mathrm{Au}$ WW, Treloar HB, Greer CA (2002) Sublaminar organization of the mouse olfactory bulb nerve layer. J Comp Neurol 446:68-80.

Bunge MB (2002) Bridging the transected or contused adult rat spinal cord with Schwann cell and olfactory ensheathing glia transplants. Prog Brain Res 137:275-282.

Camand E, Morel MP, Faissner A, Sotelo C, Dusart I (2004) Long-term changes in the molecular composition of the glial scar and progressive increase of serotoninergic fibre sprouting after hemisection of the mouse spinal cord. Eur J Neurosci 20:1161-1176.

Carter LA, MacDonald JL, Roskams AJ (2004) Olfactory horizontal basal cells demonstrate a conserved multipotent progenitor phenotype. J Neurosci 24:5670-5683.

Chernousov MA, Scherer SS, Stahl RC, Carey DJ (1999) p200, a collagen secreted by Schwann cells, is expressed in developing nerves and in adult nerves following axotomy. J Neurosci Res 56:284-294.

Chuah MI, Choi-Lundberg D, Weston S, Vincent AJ, Chung RS, Vickers JC, West AK (2004) Olfactory ensheathing cells promote collateral axonal branching in the injured adult rat spinal cord. Exp Neurol 185:15-25.

Doucette R (1990) Glial influences on axonal growth in the primary olfactory system. Glia 3:433-449.

Fouad K, Schnell L, Bunge MB, Schwab ME, Liebscher T, Pearse DD (2005) Combining Schwann cell bridges and olfactory-ensheathing glia grafts with chondroitinase promotes locomotor recovery after complete transection of the spinal cord. J Neurosci 25:1169-1178.

Franklin RJ, Gilson JM, Franceschini IA, Barnett SC (1996) Schwann celllike myelination following transplantation of an olfactory bulbensheathing cell line into areas of demyelination in the adult CNS. Glia $17: 217-224$

Garcia-Alias G, Lopez-Vales R, Fores J, Navarro X, Verdu E (2004) Acute transplantation of olfactory ensheathing cells or Schwann cells promotes recovery after spinal cord injury in the rat. J Neurosci Res 75:632-641.

Graziadei PP, Levine RR, Graziadei GA (1978) Regeneration of olfactory axons and synapse formation in the forebrain after bulbectomy in neonatal mice. Proc Natl Acad Sci USA 75:5230-5234.

Graziadei PP, Levine RR, Monti Graziadei GA (1979) Plasticity of connections of the olfactory sensory neuron: regeneration into the forebrain following bulbectomy in the neonatal mouse. Neuroscience 4:713-727.

Hobson MI, Green CJ, Terenghi G (2000) VEGF enhances intraneural angiogenesis and improves nerve regeneration after axotomy. J Anat 197:591-605.

Hofstetter CP, Holmstrom NA, Lilja JA, Schweinhardt P, Hao J, Spenger C, Wiesenfeld-Hallin Z, Kurpad SN, Frisen J, Olson L (2005) Allodynia limits the usefulness of intraspinal neural stem cell grafts; directed differentiation improves outcome. Nat Neurosci 8:346-353.

Huang H, Chen L, Wang H, Xiu B, Li B, Wang R, Zhang J, Zhang F, Gu Z, Li Y, Song Y, Hao W, Pang S, Sun J (2003) Influence of patients' age on functional recovery after transplantation of olfactory ensheathing cells into injured spinal cord injury. Chin Med J (Engl) 116:1488-1491.

Imaizumi T, Lankford KL, Waxman SG, Greer CA, Kocsis JD (1998) Transplanted olfactory ensheathing cells remyelinate and enhance axonal conduction in the demyelinated dorsal columns of the rat spinal cord. J Neurosci 18:6176-6185.

Jang JH, Nam TS, Paik KS, Leem JW (2004) Involvement of peripherally released substance $\mathrm{P}$ and calcitonin gene-related peptide in mediating mechanical hyperalgesia in a traumatic neuropathy model of the rat. Neurosci Lett 360:129-132.

Jani HR, Raisman G (2004) Ensheathing cell cultures from the olfactory bulb and mucosa. Glia 47:130-137.

Kauppila T (1998) Correlation between autotomy-behavior and current theories of neuropathic pain. Neurosci Biobehav Rev 23:111-129.

Keyvan-Fouladi N, Raisman G, Li Y (2003) Functional repair of the corticospinal tract by delayed transplantation of olfactory ensheathing cells in adult rats. J Neurosci 23:9428-9434.

Lakatos A, Franklin RJ (2002) Transplant mediated repair of the central nervous system: an imminent solution? Curr Opin Neurol 15:701-705.

Lakatos A, Franklin RJ, Barnett SC (2000) Olfactory ensheathing cells and Schwann cells differ in their in vitro interactions with astrocytes. Glia 32:214-225.

Lakatos A, Barnett SC, Franklin RJ (2003) Olfactory ensheathing cells induce less host astrocyte response and chondroitin sulphate proteoglycan expression than Schwann cells following transplantation into adult CNS white matter. Exp Neurol 184:237-246.

Li Y, Field PM, Raisman G (1998) Regeneration of adult rat corticospinal axons induced by transplanted olfactory ensheathing cells. J Neurosci 18:10514-10524.

Li Y, Decherchi P, Raisman G (2003) Transplantation of olfactory ensheathing cells into spinal cord lesions restores breathing and climbing. J Neurosci 23:727-731.

Lipson AC, Widenfalk J, Lindqvist E, Ebendal T, Olson L (2003) Neurotrophic properties of olfactory ensheathing glia. Exp Neurol 180:167-171.

Loy DN, Crawford CH, Darnall JB, Burke DA, Onifer SM, Whittemore SR (2002) Temporal progression of angiogenesis and basal lamina deposition after contusive spinal cord injury in the adult rat. J Comp Neurol 445:308-324.

Lu J, Feron F, Ho SM, Mackay-Sim A, Waite PM (2001) Transplantation of nasal olfactory tissue promotes partial recovery in paraplegic adult rats. Brain Res 889:344-357.

Lu J, Feron F, Mackay-Sim A, Waite PM (2002) Olfactory ensheathing cells promote locomotor recovery after delayed transplantation into transected spinal cord. Brain 125:14-21.

Moreau-Fauvarque C, Kumanogoh A, Camand E, Jaillard C, Barbin G, Boquet I, Love C, Jones EY, Kikutani H, Lubetzki C, Dusart I, Chedotal A (2003) The transmembrane semaphorin Sema4D/CD100, an inhibitor of axonal growth, is expressed on oligodendrocytes and upregulated after CNS lesion. J Neurosci 23:9229-9239.

Nash HH, Borke RC, Anders JJ (2002) Ensheathing cells and methylprednisolone promote axonal regeneration and functional recovery in the lesioned adult rat spinal cord. J Neurosci 22:7111-7120.

Pearse DD, Marcillo AE, Oudega M, Lynch MP, Wood PM, Bunge MB (2004) Transplantation of Schwann cells and olfactory ensheathing glia after spinal cord injury: does pretreatment with methylprednisolone and interleukin-10 enhance recovery? J Neurotrauma 21:1223-1239.

Rabinovich SS, Seledtsov VI, Poveschenko OV, Senuykov VV, Taraban VY, Yarochno VI, Kolosov NG, Savchenko SA, Kozlov VA (2003) Transplantation treatment of spinal cord injury patients. Biomed Pharmacother $57: 428-433$.

Ramer LM, Richter MW, Roskams AJ, Tetzlaff W, Ramer MS (2004a) Peripherally-derived olfactory ensheathing cells do not promote primary afferent regeneration following dorsal root injury. Glia 47:189-206.

Ramer LM, Au E, Richter MW, Liu J, Tetzlaff W, Roskams AJ (2004b) Peripheral olfactory ensheathing cells reduce scar and cavity formation and promote regeneration after spinal cord injury. J Comp Neurol 473:1-15.

Ramon-Cueto A, Nieto-Sampedro M (1994) Regeneration into the spinal cord of transected dorsal root axons is promoted by ensheathing glia transplants. Exp Neurol 127:232-244.

Ramon-Cueto A, Plant GW, Avila J, Bunge MB (1998) Long-distance axonal regeneration in the transected adult rat spinal cord is promoted by olfactory ensheathing glia transplants. J Neurosci 18:3803-3815.

Ramon-Cueto A, Cordero MI, Santos-Benito FF, Avila J (2000) Functional recovery of paraplegic rats and motor axon regeneration in their spinal cords by olfactory ensheathing glia. Neuron 25:425-435.

Riddell JS, Enriquez-Denton M, Toft A, Fairless R, Barnett SC (2004) Olfactory ensheathing cell grafts have minimal influence on regeneration at the dorsal root entry zone following rhizotomy. Glia 47:150-167. 
Sasaki M, Lankford KL, Zemedkun M, Kocsis JD (2004) Identified olfactory ensheathing cells transplanted into the transected dorsal funiculus bridge the lesion and form myelin. J Neurosci 24:8485-8493.

Schwab ME (2002) Repairing the injured spinal cord. Science 295:1029-1031.

Senior K (2002) Olfactory ensheathing cells to be used in spinal-cord repair trial. Lancet Neurol 1:269.

Sonigra RJ, Brighton PC, Jacoby J, Hall S, Wigley CB (1999) Adult rat olfactory nerve ensheathing cells are effective promoters of adult central nervous system neurite outgrowth in coculture. Glia 25:256-269.

Wall PD (1979) Substantia gelatinosa and the control of somato-sensory transmission. Int Rehabil Med 1:106-110.

Williams SK, Franklin RJ, Barnett SC (2004) Response of olfactory en- sheathing cells to the degeneration and regeneration of the peripheral olfactory system and the involvement of the neuregulins. J Comp Neurol 470:50-62.

Woodhall E, West AK, Chuah MI (2001) Cultured olfactory ensheathing cells express nerve growth factor, brain-derived neurotrophic factor, glia cell line-derived neurotrophic factor and their receptors. Brain Res Molecular Brain Res 88:203-213.

Zigova T, Graziadei PP, Monti-Graziadei AG (1992) Olfactory bulb transplantation into the olfactory bulb of neonatal rats: a WGA-HRP study. Brain Res 588:6-12.

Zimmermann M (2001) Pathobiology of neuropathic pain. Eur J Pharmacol 429:23-37. 